\title{
BCG vaccinaton scars of childen under five years in a tertiary care hospital
}

\author{
N Srisaravanapavananthan ${ }^{1}$, N N Dissanayake ${ }^{1}$, Jeevani Sarathchandra ${ }^{2}$ \\ Sri Lanka Journal of Child Health, 2008; 37: 81-84
}

(Key words: BCG vaccine, BCG scar, revaccination, tuberculosis, protective efficacy)

\begin{abstract}
Objective To study the BCG vaccination scars of under 5 year old children who were admitted to a tertiary care hospital

Design Cross sectional descriptive study

Setting Ward 3, Lady Ridgeway Hospital for Children (LRH)
\end{abstract}

Method All children between 6 and 60 months of age, admitted to ward $3 \mathrm{LRH}$ from October $15^{\text {th }}$ to December $30^{\text {th }} 2006$, were included in the study. The interviewer-administered questionnaire and examination of the child for BCG scar were the methods used to collect the data.

Results: Of 1010 patients admitted to ward $3 \mathrm{LRH}$ during the study period, 923 were analysed. BCG vaccine had been given to all patients. Whilst 821 (89\%) patients had the BCG scar, 102 (11\%) did not have it. Among patients with the BCG scar, 20\% had received $\mathrm{BCG}$ vaccine in non tertiary care hospitals, whereas in patients with absent BCG scar, this figure was $35 \%(p=0.003 ; p<0.05)$. In the Child Health Development Record (CHDR), the BCG scar column had been marked in only 554 (64\%). Among 102 patients with absent BCG scar, revaccination was not indicated in $20(21 \%)$ because the BCG scar had been marked as positive in the CHDR. However, 96 had not been revaccinated. Common reasons for non revaccination were: unawareness of mothers regarding absent BCG scar (38.5\%) and postponement of revaccination $(24 \%)$.

Conclusion There was a significant number of patients with absent BCG scars indicating need for larger scale studies.

\footnotetext{
${ }^{1}$ Senior Registrar, ${ }^{2}$ Consultant Paediatrician, Lady Ridgeway Hospital, Colombo
}

(Received on 10 March 2008. Accepted after revision on 2 April 2008)

\section{Introduction}

The main benefit of BCG vaccination is that there is a $50-80 \%$ protective effect against disseminated TB, TB meningitis or miliary TB which occur more often in under 5 year old children ${ }^{1,2}$. Absent BCG scar is a common occurrence. In our unit we diagnosed TB meningitis in two patients who had no BCG scar though BCG had been given at birth. There are controversies regarding the practice of repeat $\mathrm{BCG}$ vaccination in children without BCG scar. Hence, we decided to perform this study.

\section{Objectives}

To study the BCG vaccination scars of under 5 year old children who were admitted to a tertiary care hospital by assessing:

1. the proportion of patients without a BCG scar.

2. whether revaccination was done in the case of absent BCG scar and if not, the reasons for non revaccination.

3. whether any relationship exists between maternal education and revaccination.

4. whether there is any association between absent BCG scar and the category of hospital/clinic where the BCG was given.

\section{Method}

A cross sectional descriptive study was carried out in ward 3, Lady Ridgeway Hospital for Children, Colombo (LRH). This hospital is the premier children's hospital in Sri Lanka getting a considerable number of patients from all over the island.

All children between 6 and 60 months of age, admitted to ward 3 for a period of $2 \frac{1}{2}$ months from October $15^{\text {th }}$ to December $30^{\text {th }} 2006$, were included in the study. 
A pretested interviewer-administered questionnaire and examination of the child to look at the BCG scar were the methods used. Interviewers were house officers and medical students who were trained to collect data and examine to look for the BCG scar. Data analysis was done using SPSS-14 software

\section{Results}

Ward 3, LRH had 1010 in-ward patients between 6 and 60 months of age from $15^{\text {th }}$ October to $30^{\text {th }}$ December 2006. Out of this, 923 patients were included in the analysis .Others were excluded due to unavailable or incomplete data. Out of 923 patients, 102 (11\%) patients did not have the BCG scar. Tables $1 \& 2$ show the distribution of patients, according to age and gender, in children with and without BCG scars.

Table 1

Distribution of patients according to age $\&$ gender in children with BCG scars

\begin{tabular}{|c|c|c|c|c|}
\hline \multirow{2}{*}{$\begin{array}{c}\text { Age } \\
\text { Grout } \\
\text { (months) }\end{array}$} & \multicolumn{4}{|c|}{ BCG scar +} \\
\cline { 2 - 5 } & & Male & Female & \multicolumn{2}{|c|}{ Total } \\
\cline { 4 - 5 } & & & No & $\%$ \\
\hline $6-12$ & 126 & 79 & 205 & 250 \\
\hline $13-24$ & 123 & 97 & 220 & 26.8 \\
\hline $25-36$ & 100 & 75 & 175 & 21.3 \\
\hline $37-48$ & 64 & 54 & 118 & 14.4 \\
\hline $49-60$ & 57 & 46 & 103 & 12.5 \\
\hline Total & $470 \mathbf{6 7 \%}$ & $\mathbf{3 5 1} \mathbf{4 3 9} \%$ & $\mathbf{8 2 1}$ & $\mathbf{1 0 0}$ \\
\hline
\end{tabular}

Table 2

Distribution of patients according to age \& gender in children without BCG scars

\begin{tabular}{|c|c|c|c|c|}
\hline \multirow{3}{*}{$\begin{array}{c}\text { Age } \\
\text { Group } \\
\text { (months) }\end{array}$} & \multicolumn{4}{|c|}{ BCG scar - } \\
\hline & \multirow[t]{2}{*}{ Male } & \multirow[t]{2}{*}{ Female } & \multicolumn{2}{|c|}{ Total } \\
\hline & & & No & $9_{10}$ \\
\hline $6-12$ & 22 & 12 & 34 & 333 \\
\hline $13-24$ & 23 & 16 & 39 & 382 \\
\hline $25-36$ & 07 & $\overline{D Q}$ & 15 & 14.7 \\
\hline $37-48$ & $\overline{05}$ & 06 & 11 & 10.8 \\
\hline $49-60$ & D1 & 02 & 03 & 030 \\
\hline Total & $58(57 \%)$ & $44(43)$ & 102 & 100 \\
\hline
\end{tabular}

The mean age of the study population was $26.7 \pm 16.3$ months. While the mean age of patients with BCG scars was $27.5 \pm 15.4$ months, the mean age for patients with absent BCG scars was $20.9 \pm 13.4$ months. There was a significant number of patients with absent BCG scars in the younger age groups $\left(<24\right.$ months) than in the older age groups. $\left(\mathrm{X}^{2}\right.$ test $\mathrm{p}=0.002 ; \mathrm{p}<0.005)$

The patients with BCG scars category had $57 \%$ boys and $43 \%$ girls. Similarly $57 \%$ of patients with absent
BCG scars were boys and $43 \%$ were girls. There was no gender variation in the presence or absence of BCG scars $\left(X^{2}\right.$ test $\left.p=0.51 ; p>0.05\right)$.

All patients had been given the BCG vaccine. This was confirmed by referring to the Child Health Development Record (CHDR). Among them only 7 $(0.8 \%)$ patients received delayed vaccination (mostly after 2 weeks) and all of them had BCG scars. The main reason for delay in vaccination was stay in the special care baby units. In this study, 369 children had the old form of CHDR which does not have the column to mark the BCG scar. The new type of CHDR has been available island-wide only since end of year 2003. However, only in 554 (64\%) of CHDR the column had been marked.

Among patients with BCG scars, $20 \%$ had been vaccinated in non tertiary care hospitals whereas for patients without BCG scars this figure was 35\% $(p=0.003 ; p<0.005)$. (Tertiary care hospitals are Teaching General Hospitals and Provincial General Hospitals).

The mean maternal education was grade $10.15 \pm 2.9$ in the study population. When we grouped the educational level (table 3 ), the mode and median educational levels were grade $11($ G.C.E.O/L) in both $\mathrm{BCG}$ scar positive and negative patients.

Table 3

Presence or absence of BCG scars according to maternal educational levels

\begin{tabular}{|c|c|c|}
\hline $\begin{array}{c}\text { Maternal } \\
\text { education }\end{array}$ & BCG scar + & BCG scar - \\
\hline Grade $<5$ & $64(07.8 \%)$ & $15(14.7 \%)$ \\
\hline Grade $6-10$ & $248(33.0 \%)$ & $28(27.5 \%)$ \\
\hline G.C.E.O/L & $311(37.9 \%)$ & $31(30.3 \%)$ \\
\hline G.C.E.A/L & $181(22.2 \%)$ & $26(25.5 \%)$ \\
\hline Graduate & $17(02.1 \%)$ & $02(02.0 \%)$ \\
\hline Total & $\mathbf{8 2 1}(\mathbf{1 0 0} \%)$ & $\mathbf{1 0 2 ( 1 0 0 \% )}$ \\
\hline
\end{tabular}

Among the patients with BCG scars, 14 had developed BCG scar due to revaccination.

Out of 102 patients with absent BCG scar, 96 (94\%) had not been revaccinated while 6 patients had not developed BCG scar even after revaccination. Revaccination had not been indicated in $20(20 \%)$ because the BCG scar had been marked as positive in the CHDR. In $76(75 \%)$ we were unable to get the BCG scar information by referring to the CHDR because either BCG scar column had not been marked or there was no BCG column to mark BCG scar in the old form of the CHDR. 
There was a significant association between the reasons for non revaccination and poor maternal education, defined as educational level $<$ grade $10(\mathrm{p}=$ $0.006 ; \mathrm{p}<0.05)$. Reasons for non revaccination in absent BCG scar patients are given in table 4.

Table 4

Reasons for non revaccination in absent BCG scar patients

\begin{tabular}{|c|c|c|}
\hline Reason & No & 9 \\
\hline $\begin{array}{l}\text { Thother unaware of absent } \mathrm{BCC} \\
\text { soar and no details about } \mathrm{BCC} \\
\text { soar in CHDR }\end{array}$ & 37 & 38.5 \\
\hline $\begin{array}{l}\text { Thother aware about absent } \mathrm{BCG} \\
\text { scar, but didr't seek advice ard } \\
\text { no details about BCG scar ir } \\
\text { CHDR }\end{array}$ & 16 & 16.5 \\
\hline $\begin{array}{l}\text { Whother went for revaccination, } \\
\text { but revaciration postponed ard } \\
\text { no details about BCG soar ir } \\
\text { CHDR. }\end{array}$ & 23 & 24.0 \\
\hline $\begin{array}{l}\text { BCCG goar rarked as positre ir } \\
\text { CHDR so that repeat } \mathrm{BCC} \\
\text { vacoine had rot been given }\end{array}$ & 20 & 21.0 \\
\hline Total & 96 & 100 \\
\hline
\end{tabular}

Common reasons for postponement of revaccination were: mothers being asked to bring their babies after about 1 year and minor illness like upper respiratory tract infection.

In this study, there were no patients who were diagnosed to have TB during their hospital stay or in the past. However, among 923 patients 11 patients were found to have a close contact history of TB. All the patients with contact history of TB were screened for TB.

\section{Discussion}

According to the Expanded Program of Immunization (EPI), BCG vaccine has to be administered between 12 hours after delivery and before discharge from the hospital or within 4 weeks of delivery ${ }^{2}$. In this study almost $99 \%$ of patients were vaccinated within one week after delivery. The remaining $1 \%$ was given $\mathrm{BCG}$, at a later time due to stay in special care baby unit. In Sri Lanka, EPI coverage assessment surveys have indicated that there is almost $100 \%$ coverage for $\mathrm{BCG}^{2,3}$. This finding was found in our study too..

On intradermal administration of BCG vaccine a swelling appears at the site of injection. Two or three weeks later a small red slightly tender swelling develops into a small abscess which ulcerates and crusts. The crusts disappear leaving a small red swollen scar which becomes smaller, paler and sunken and remains for years ${ }^{2}$.

Complications could develop after BCG vaccination in infants including local ulcers and regional lymphadenitis (4 to 30 per 1000 vaccinated infants), osteomyelitis (0.1 to 30 per 100,000 doses), disseminated BCG infection (0.1 per 100,000 doses) and death $(0.02 \text { per million })^{4}$. In our study, only one patient had BCG adenitis following vaccination.

Absence of BCG scar is commonly seen in children. This study revealed $11 \%$ of patients did not have BCG scars. Similar results were found in previous Sri Lankan studies ${ }^{2,5}$. The reason for non-development of scar may be

1. Faulty technique, including leaving the prepared vaccine for long periods, leaving the prepared vaccine near a flame or indirect sunlight and injecting subcutaneously instead of intradermally ${ }^{2}$. In our study a significant number patients with absent BCG scars were given BCG vaccine in the hospitals or clinics other than the TGH/PGH. The above mentioned factors, limited facilities and inexperienced staffs may contribute to this finding.

2. Use of vaccine which is not potent ${ }^{2}$. In this study, there was a significant number of patients without BCG scar who were less than 24 months of age (these children were born in the period between October 2004 and April 2006). The vaccine used during that period was imported from India (Serum institute, India) and prior to year 2004; the vaccine was imported from Denmark and Japan. (source Epidemiology unit). We do not know whether the vaccine potency was different.

3. BCG might not have been given even though an entry was made. This could happen, since the cards are usually completed before the vaccination is given. Some mothers could slip away with their babies during this procedure. This could happen if mothers' education is poor. We did not find significant association between maternal education and the absence of BCG scar $(\mathrm{P}=0.065 ; \mathrm{p}>0.05)$.

4. The immune response system may not have been developed sufficiently immediately after delivery. There is some evidence to suggest that later immunization during infancy may confer a higher degree of immunity ${ }^{6}$. A study which was 
conducted in 1990 in the Northern Province of Sri Lanka, revealed a significant number of infants who had been given BCG vaccine at birth but did not develop BCG scar in contrast to the babies vaccinated in the clinics at a later time ${ }^{2}$. However, in our study; less than $1 \%$ of patients were given $\mathrm{BCG}$ vaccine at a later time.

There are controversies regarding revaccination of BCG. One suggests that repeated BCG vaccinations might be effective in asthma therapy ${ }^{7}$. Studies have shown that BCG vaccine protects leprosy ${ }^{8}$. However, repeat vaccination is not recommended by WHO as there is no evidence for the efficacy of BCG revaccination ${ }^{9}$. Furthermore, the formation of scar is not the only indication of success of BCG vaccine. However it is the only simple \& convenient way of determining success of BCG vaccine. It may take 3-6 months for the scar to form. If no scar is visible at all after 6 months one should give repeat $\mathrm{BCG}^{10,11}$. Such vaccination can be restricted to children up to 5 years who are most vulnerable to miliary and meningial forms of tuberculosis ${ }^{12}$. In Sri Lanka, The National Programme for Tuberculosis Control and Chest Diseases recommends repeat vaccination in case of absent BCG scar ${ }^{4}$. In our study, a significant percentage of non revaccination was found, in case of absent BCG scar. Non revaccination was mainly associated with poor maternal education.

\section{Conclusions and recommendations}

A significant number of patients did not have a BCG scar after 6 months of age. A significant proportion of patients with absent BCG scar had been vaccinated in the non tertiary care hospitals. Larger scale studies are needed to confirm these findings. Majority of patients with absent BCG scars, had not been revaccinated. It is necessary to train the health staff in peripheral hospitals and educate mothers regarding $B C G$ vaccination and scar.

\section{Acknowledgements}

The contribution made by the medical students of the University of Colombo and House Officers of ward 3, Lady Ridgeway Hospital is greatly appreciated.

\section{References}

1. Colditz GA, Brewer TF, Berkey CS, Wilson ME, Burdick E, Fineberg HV, et al. Efficacy of BCG vaccine in the prevention of tuberculosis. Metaanalysis of the published literature. JAMA. 1994; 271(9):698-702.
2. Sivarajah N, Sivayogan S, Jegatheesan J, Gnananathan V. BCG vaccination and development of a scar. CMJ. 35(2):1990; 75-78.

3. Ministry of Health; Sri Lanka.Annual Health Bulletin; 2003: table 52.

4. Bolger T, O'Connell M, Menon A, Butler K. Complications associated with the bacilli Calmette-Guérin vaccination in Ireland. Arch. Dis Child .2006; 91:594-7.

5. Fernando WDD, Hafrath MR, Perera J. BCG vaccination and scar formation, comparative analysis of state sector vaccines and non state sector vaccines. PP 06.SLMA $116^{\text {th }}$ Anniversary Academic Sessions, Programme and abstract book. SLMA. 2003. p 60-61.

6. Bannon MJ. BCG and Tuberculosis. Arch.Dis child .1999; 80:80-3.

7. Choi IS, Koh YI. Effects of BCG revaccination on asthma .Allergy. 2003; 58: 1114-6.

8. Rahete NP, Zodpey SP, Kamble KM. Effectiveness of Bacillus Calmette Guerin (BCG) vaccination in the prevention of leprosy: a population-based case-control study in Raipur, India. IndianJPublicHealth.2007; 51(2):86-90.

9. Tam CM, Leung CC. Cessation of the BCG (Bacille Calmette Guerin) revaccination programme for primary school children in Hong Kong Public Health \& Epidemiology Bulletin 2000;9(3): 25-7.

10. Bothamley GH, Ed Cooper, Shingadia D, Mellanby A. Tuberculin testing before BCG vaccination. $B M J$.327: 2003; 243-4.

11. National Programme for Tuberculosis Control and Chest Diseases; Ministry of Health. Sri Lanka. General Manual for Tuberculosis Control. $2^{\text {nd }}$ ed. 2005.

12. Goyal $\mathrm{R}, \mathrm{BCG}$ vaccination in $\mathrm{BCG}$ scar negative children, Indian Paediatrics .1998; 35:570. 